\title{
Smoking in Crohn's disease: effect on localisation and clinical course
}

\author{
E Lindberg, G Järnerot, B Huitfeldt
}

\begin{abstract}
The effects of smoking on the localisation and clinical course of Crohn's disease is evaluated in 231 patients. Heavy smokers ( $>10$ cigarettes/ day) had an increased risk of operation at least once-odds ratios for heavy smokers compared with never smokers after five and 10 years were 1.14 and 1.24 respectively $(p=0.03$ and $p=0.017$ ). The risk of further operations was even higher and after 10 years the odds ratio was $1.79(p=0 \cdot 015)$. The accumulated number of fistulae and/or abscesses was higher for smokers than for never smokers $(p=0.046)$. Patients with a high life time tobacco exposure (>150 cigarette years) and heavy smokers ( $>10$ cigarettes/day) had small bowel disease more often than patients with lower life time exposure ( $\leqslant 150$ cigarette years) and patients smoking $\leqslant 10$ cigarettes/day $(p=0.002$ and $p=0.045$ respectively). The course of Crohn's disease analysed in different ways was unfavourable for smokers, especially heavy smokers. Patients with Crohn's disease should be dissuaded from smoking.
\end{abstract}

Somerville et $a l^{1}$ showed in 1984 that patients with Crohn's disease were more often smokers than controls. This has been verified by others in studies comparing patients with Crohn's disease with population controls, patients with ulcerative colitis or irritable bowel syndrome..$^{2-10}$ Little is known whether or not smoking affects the localisation or course of the disease. The aim of the present study was to investigate this.

\section{Methods}

PATIENTS

Patients with Crohn's disease residing within the immediate catchment area of the Medical Center Hospital, Örebro, Sweden were approached. The patient population has been described elsewhere. ${ }^{11}$ A questionnaire about previous and present smoking habits was sent to 250 patients with Crohn's disease. Diagnosis was based on the clinical history, endoscopy and/or radiology together with histology reports and negative faecal culture. All medical records were scrutinised to confirm or exclude the earlier diagnosis of Crohn's disease.

The distribution of disease at the time of the diagnosis was obtained from the medical notes and classified as: (a) small bowel only, (b) small plus large bowel (also including small bowel plus caecal involvement) and (c) large bowel only. For ethical reasons radiology was not repeated to obtain information on localisation of the disease at the time of follow up. Thus, we have incom- plete data in this respect and no analysis has been performed regarding change of localisation.

The number of surgical procedures carried out for Crohn's disease was registered. These procedures have been defined as resection and/or stricture plasty. Minor operations such as drainage of perianal abscesses or cleavage of perianal fistulae, operations for adhesions without bowel resection or stricture plasty and minor stomal revisions have not been included.

Disease complications such as fistulae and/or abscesses localised perianally or elsewhere at the time of diagnosis and during the follow up were registered.

In order to evaluate whether or not smoking habits had any influence on the localisation of the disease or the occurrence of fistulae and/or abscesses at the time of diagnosis the smokers were divided into different groups. The effect of the daily number of cigarettes consumed irrespective of the life time exposure was studied by dividing the smokers into consuming $\leqslant 10$ or $>10$ cigarettes/day. We have attempted to evaluate the importance of the total cigarette exposure before diagnosis by calculating the number of cigarette years for each patient using the formula: number of cigarettes/day $\times$ years of smoking before diagnosis, a method similar to the one used by Boyko et al. ${ }^{12}$ Smokers were then arbitrarily divided into those with $\leqslant 150$ or $>150$ cigarette years.

For evaluation of the influence of smoking on the course of disease only those patients who had remained never smokers or smokers were included. Those who had changed their smoking pattern were excluded, as well as former smokers because the small number of these precluded meaningful analysis.

\section{STATISTICAL ANALYSIS}

The analysis was done using the statistical software program $\mathrm{BMDP}^{13}$ : $1 \mathrm{D}$ for organisation of data; $4 \mathrm{~F}$ for analysis of frequency tables and odds ratio and $1 \mathrm{~L}$ for life tables. The study was approved by the Ethical Committee, Örebro Medical Center Hospital.

\section{Results}

After a second letter 238 of the 250 patients (95.2\%) responded, four patients having died and eight not responding. Seven of the 238 patients were later excluded from the study because of uncertain diagnosis. Thus, the material analysed comprised 231 patients. Of these $96(42 \%)$ were never smokers, $17(7 \%)$ former smokers and $118(51 \%)$ smokers at the time of diagnosis. The daily cigarette consumption at diagnosis could be determined with 
certainty for 113 patients, whereby 49 smoked $\leqslant 10$ cigarettes and $64>10$ cigarettes/day. The number of cigarette years could be calculated for 112 patients. Sixty six had $\leqslant 150$ and $46>150$ cigarette years. Forty one patients had changed their smoking habits and were excluded from the statistical analysis on the effect of smoking on the course of the disease. This analysis which thus comprised 81 never smokers and 92 smokers, former smokers having also been excluded. Of the smokers 37 smoked $\leqslant 10$ and $54>10$ cigarettes/day while the daily consumption was uncertain in one patient.

Table I shows the median age of the patients at the time of diagnosis. Former smokers and patients with $>150$ cigarette years were older than smokers and never smokers at the time of diagnosis which is an obvious consequence and therefore no statistical analysis of age distribution has been done. Table II illustrates the observation time which showed no significant variation between never smokers and smokers independent of daily consumption.

Table III shows the localisation of the disease at the time of diagnosis. The never smoking, former smoking or smoking groups did not vary significantly in this respect $\left(\chi^{2}=4 \cdot 61, p=0.329\right.$, $\mathrm{df}=4)$.

When smokers were divided into those smoking $\leqslant 10$ or $>10$ cigarettes/day small bowel

TABLE I Smoking data in the studied Crohn's disease population and the median age (years) at diagnosis in different groups Cig/day= the number of cigarettes consumed per day at time of survey. The daily cigarette consumption could be decided for 113 patients. Cig years is calculated from the formula: number of cigarettes per day $\times$ years of smoking. This could be calculated for 112 patients

\begin{tabular}{lll}
\hline & $\begin{array}{l}\text { Patients } \\
(n)\end{array}$ & $\begin{array}{l}\text { Median age } \\
\text { at diagnosis } \\
\text { (range) }\end{array}$ \\
\hline Smokers & 118 & $28(13-71)$ \\
$\leqslant 10$ cig/day & 49 & $30(17-64)$ \\
$>10$ cig/day & 64 & $27(13-71)$ \\
$\leqslant 150$ cig years & 66 & $23 \cdot 5(13-58)$ \\
$>150$ cig years & 46 & $38(22-71)$ \\
Never smokers & 96 & $24 \cdot 5(7-73)$ \\
Former smokers & 17 & $38(22-63)$ \\
\hline
\end{tabular}

TABLE II Median observation time (years) and range of Crohn's diseased patients who have remained smokers and never smokers respectively during observation time. The daily cigarette consumption was uncertain for one patient

\begin{tabular}{lll}
\hline & $\begin{array}{l}\text { Median } \\
\text { observation } \\
\text { time after } \\
\text { diagnosis } \\
\text { (range) }\end{array}$ \\
\hline Smokers & $(n)$ & $10(1-26)$ \\
$\leqslant 10$ cig/day & 92 & $8(1-26)$ \\
$>10$ cig/day & 37 & $12(1-26)$ \\
Never smokers & 54 & $9(1-34)$ \\
\hline
\end{tabular}

TABLE III Distribution of Crohn's disease at time of diagnosis. Percentage within brackets. The daily cigarette consumption could be decided for 113 patients and the number of cigarette years (number of cigarettes/day $\times$ years of smoking) could be calculated for 112 patients

\begin{tabular}{lcccc}
\hline & $\begin{array}{l}\text { Patients } \\
(n)\end{array}$ & $\begin{array}{l}\text { Small bowel } \\
\text { disease }\end{array}$ & $\begin{array}{l}\text { Colonic } \\
\text { disease }\end{array}$ & $\begin{array}{l}\text { Combined small } \\
\text { and large bowel }\end{array}$ \\
\hline Never smokers & 96 & $18(19)$ & $14(15)$ & $64(67)$ \\
Former smokers & 17 & $5(29)$ & $4(24)$ & $8(47)$ \\
Smokers & 118 & $32(27)$ & $13(11)$ & $73(62)$ \\
$\leqslant 10$ cig/day & 49 & $8(16)$ & $8(16)$ & $33(67)$ \\
$>10$ cig/day & 64 & $23(36)$ & $5(8)$ & $36(56)$ \\
$\leqslant 150$ cig years & 66 & $10(15)$ & $9(14)$ & $47(71)$ \\
$>150$ cig years & 46 & $21(46)$ & $3(7)$ & $22(48)$ \\
\hline
\end{tabular}

disease was more frequent than isolated colonic or combined small and large bowel disease at diagnosis in those smoking $>10$ cigarettes/day $\left(\chi^{2}=6 \cdot 20, p=0 \cdot 045, d f=2\right)$. This was even more pronounced when smokers were analysed for total cigarette exposure, $>150$ cigarette years versus $<150$ cigarette years $\left(\chi^{2}=12 \cdot 80, \mathrm{p}=\right.$ $0.002, \mathrm{df}=2$ ) (Table III).

The occurrence of fistulae and/or abscesses at diagnosis did not vary between the groups nor did daily cigarette consumption have any impact on the occurrence of such complications. The accumulated number of fistulae and/or abscesses, however, was higher among smokers than never smokers $\left(\chi^{2}=3 \cdot 99, \mathrm{p}=0 \cdot 046, \mathrm{df}=1\right)$. (Table IV.)

As seen in Table $V$, the proportion of never smokers not operated on was higher than in smokers, especially compared with heavy smokers. In order to investigate whether this was a true difference a life table analysis was done comparing never smokers, heavy smokers, and moderate smokers.

During the first year after diagnosis the proportion operated upon once or more was $46 \%$ of the never smokers and $56 \%$ of the heavy smokers. The corresponding figures after five years were $62 \%$ and $76 \%$ respectively and after 10 years $76 \%$ and $85 \%$ respectively (Fig 1 ).

Odds ratio for heavy smokers compared with never smokers to be operated upon at least once within the first year after diagnosis was 1.22 $\left(\mathrm{CI}_{95 \%}\right.$ 0.87-1.70), after five years the odds ratio was $1 \cdot 14\left(\mathrm{CI}_{95 \%} 1 \cdot 01-1 \cdot 27\right)$ and after 10 years $1 \cdot 24\left(\mathrm{CI}_{95 \%} 1 \cdot 04-1 \cdot 47\right)$. Odds ratio was significantly increased after five and 10 years of follow up $(p=0.030$ and $p=0.017)$ but not after one year $(\mathrm{p}=0 \cdot 254)$.

The risk of being operated upon at least twice was analysed in the same way (Fig 2). Within five years after diagnosis the proportion of never smokers, moderate smokers and smokers reoperated upon at least once was similar. Ten years after diagnosis $26 \%$ never smokers, $28 \%$ moderate smokers, and $42 \%$ heavy smokers had been reoperated upon at least once.

Odds ratio for heavy smokers compared with never smokers to be reoperated upon once or more after 10 years of follow up was $1.79\left(\mathrm{CI}_{95 \%}\right.$ $1 \cdot 12-2 \cdot 55, \mathrm{p}=0 \cdot 015)$.

\section{Discussion}

Firm evidence exists that patients with Crohn's disease are to a greater extent smokers than control subjects. It is not known if smoking is an aetiological factor or if the association has other explanations such as basic personality, long standing subclinical symptoms relieved by smoking, or changes in the biological signal system caused by a preclinical state of the disease which perhaps could make a person more prone to become a smoker. Other effects of smoking have also been discussed such as the immunosuppressive effects, influencing both cellular and humoral immunity or interference with the lipoxygenase system. ${ }^{8}$ The possible association to the well known vascular effects of smoking does not seem to have been given much attention.

In addition, disregarding the cause of the association, very little is known whether or not 
TABLE IV Numbers and percentages of patients with fistulae and/or abscesses at the time of diagnosis and during follow up. $n^{\star}$ refers to the number at diagnosis as shown in Table I; nt refers to the numbers with unchanged smoking habits during the observation period as shown in Table II. The daily cigarette consumption could be calculated for 113 patients at diagnosis and 91 patients during observation time

\begin{tabular}{lllll}
\hline & Never smokers & Smokers & $\leqslant 10$ cig/day & $>10$ cig/day \\
\hline $\begin{array}{c}\text { Patients with fistulae and/or abscesses } \\
\text { at diagnosis, } \mathrm{n}(\%)^{\star}\end{array}$ & $20(21)$ & $26(22)$ & $13(27)$ & $11(17)$ \\
$\begin{array}{c}\text { Accumulated no. of patients with } \\
\text { fistulae and/or abscesses, n(\%)t }\end{array}$ & $30(37)$ & $48(52)$ & $19(51)$ & $28(52)$ \\
\hline
\end{tabular}

TABLE V Median number and range of operations for Crohn's disease. Also shown is number and percentage of patients never operated upon. The daily cigarette consumption could be calculated for 91 patients

\begin{tabular}{lllll}
\hline & Never smokers & Smokers & $\leqslant 10$ cig/day & $>10$ cig/day \\
\hline Patients, $\mathbf{n}$ & 81 & 92 & 37 & 54 \\
Operations n (range) & $1(0-5)$ & $1(0-9)$ & $1(0-9)$ & $1(0-8)$ \\
Patients not operated $\mathbf{n}(\%)$ & $24(30)$ & $16(17)$ & $10(27)$ & $6(11)$ \\
\hline
\end{tabular}

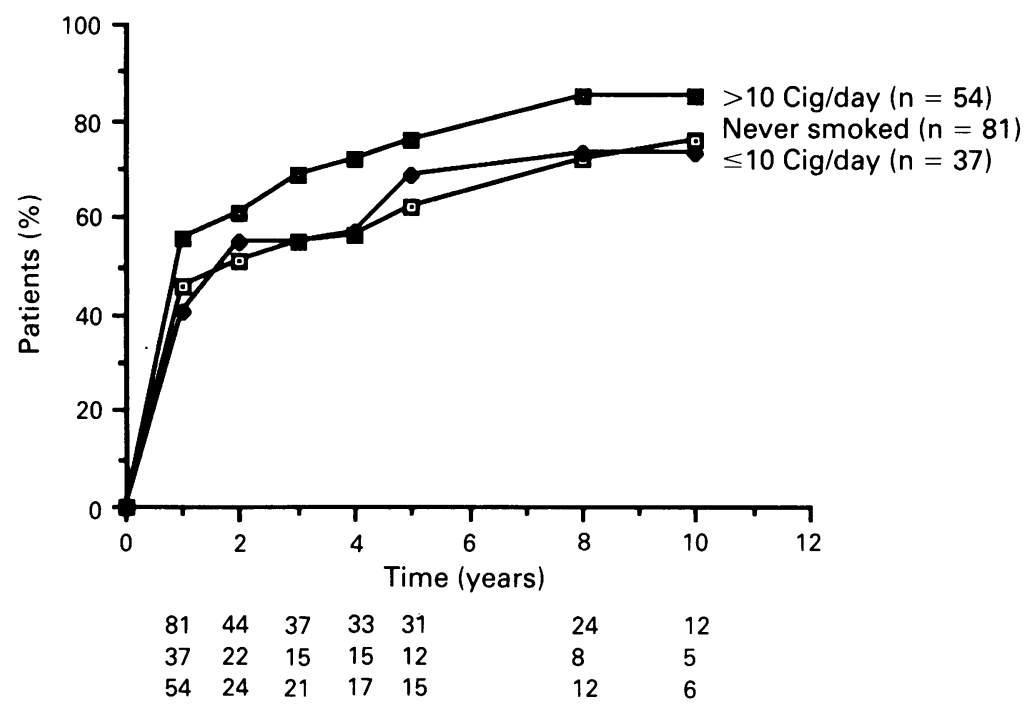

Figure 1: Percentage of patients who had been operated upon at least once, calculated for never smokers, patients smoking $\leqslant 10$ cigarettes/day or $>10$ cigarettes/day. On $X$-axis the years of follow up. Figures at the bottom denotes patients still being followed. Odds ratios to have been operated on at least once one, five, and 10 years after diagnosis were $1 \cdot 22(0 \cdot 87-1 \cdot 70), 1 \cdot 14$ $(1 \cdot 01-1 \cdot 27)$ and $1 \cdot 24(1 \cdot 04-1 \cdot 47)$ respectively for patients smoking $>10$ cig/day $\mathrm{v}$ never smokers.



Figure 2: Percentage of patients who had been operated upon at least twice, calculated for never smokers, patients smoking $\leqslant 10$ cigarettes/day or $>10$ cigarettes/day. On the $X$-axis the years of follow up. Figures at the bottom denotes patients still being followed. Odds ratio to have been operated on at least twice 10 years after diagnosis was $1 \cdot 79(1 \cdot 12-2 \cdot 55)$ for patients smoking $>10$ cig/day v never smokers. smoking affects the localisation or course of the disease. In contrast with ulcerative colitis, Crohn's disease affects the whole gastrointestinal tract from mouth to anus. Overwhelming data show that cigarette smoking decreases the risk of acquiring ulcerative colitis. ${ }^{6-101+17}$ In our study the proportion of patients with isolated colonic Crohn's disease did not vary between never smokers and smokers which indicates that cigarette smoking does not protect the colonic mucosa from Crohn's disease.

Holdstock et $a l^{3}$ interviewed 149 consecutive outpatients with Crohn's disease. They found that small bowel disease, defined as small bowel disease plus combined small bowel and colonic disease, occurred significantly more often in smokers than non-smokers. Selection bias probably influenced their results, however, making them difficult to evaluate, for instance, in their Crohn's disease population $64 \%$ had Crohn's colitis without involvement of the small bowel which is an extraordinarily high figure. Furthermore, it is not clear whether or not the nonsmoking group consisted of never smokers only or never smokers plus former smokers. If the results presented here are evaluated in a similar manner no difference between smokers and nonsmokers (never smokers plus former smokers) can be found.

When we classify the smokers according to daily tobacco consumption or total life time exposure at the time of diagnosis, however, heavy smokers ( $>10$ cigarettes/day) and those with high tobacco exposure $(>150$ cigarette years) had a significantly higher frequency of isolated small bowel disease. Somerville et al, ${ }^{\prime}$ Tobin et $a l^{7}$ and Benoni et $a l^{8}$ did not find that smoking influenced the site of disease. They did not analyse for daily consumption, however, or total cigarette exposure before diagnosis.

It is obvious that former smokers ought to be older at diagnosis and that the number of cigarette years correlates with the daily consumption and age at diagnosis. Still the combination of total tobacco exposure and increasing age makes it tempting to speculate that ischaemia is an aetiologic factor in Crohn's disease which, reasonably, ought to be more pronounced in subjects who are both heavy smokers and older than in those who are never smokers and younger. This speculation is supported by recent studies of Wakefield et $a l,{ }^{1819}$ who found multiple gastrointestinal infarction in Crohn's disease, obviously caused by granulomatous arteritis with or without thrombotic occlusion. Such lesions were also found in macroscopically uninvolved areas. If Crohn's disease is caused by a vasculitis with ischaemia, further vascular changes caused by smoking and age could aggravate the injuries making the disease clinically overt. Such a hypothesis could explain why patients with clinical Crohn's disease to a greater extent are smokers while non-smokers perhaps more often have subclinical disease. If this is the case, one would expect that smokers are more represented in patients with other vasculitides. Indeed, a study by Benoni et $a l^{20}$ showed that patients with systemic lupus erythematosus were smokers more often than population controls although the difference did not reach statistical signific- 
ance, which may be explained by the limited number of patients. We cannot explain, on the basis of the present knowledge of gut intestinal blood circulation, why the richly blood supplied small intestine should be more susceptible than the large bowel.

In their analysis Holdstock $e t a l^{3}$ found that smokers with small bowel disease tended to have more operations than non-smokers. The statistical significance was not strong $(\mathrm{p}<0.04)$, however, and could be a result of analysing 172 variables in each patient.

Sutherland $e t a l^{21}$ evaluated the effect of smoking on the need for a second resection. They found a two-fold risk for smokers to be reoperated upon after five years. The risk was even higher for women smokers with small bowel disease (odds ratio $9 \cdot 2$ ). Only $74 \%$ of their patients replied to the questionnaire, however, which decreases the validity of these figures. In our study we found a slight but statistically significant increased risk for heavy smokers compared with never smokers to be operated upon at least once within five years and 10 years of diagnosis (odds ratio $1 \cdot 14$ and $1 \cdot 24$, respectively) and also an increased risk to be reoperated at least once within 10 years (odds ratio 1.79 ). The same negative trends for smokers were also seen when calculating the accumulated number of complications as fistulae and/or abscesses. Four of the 250 patients approached had died. Their smoking habits are not known in detail but at diagnosis one of them was a never smoker and the other three smokers. Obviously these patients would not have changed the results in a way more favourable to smokers, if they had been included.

In conclusion, smokers, and in particular heavy smokers, with Crohn's disease have a worse outcome compared with never smokers, having an increased risk of operation and reoperation. Together with the other well known medical risks of smoking, this conclusion should encourage smokers with Crohn's disease to stop smoking.
This study was economically supported by Örebro County Research Committee. Eva Lindberg has been financed by AB Pharmacia, Uppsala, Sweden to do inflammatory bowel disease studies. Dr Ian Jones is gratefully acknowledged for linguistic revision.

1 Somerville KW, Logan RFA, Edmond M, Langman MJS. Smoking and Crohn's disease. BMF 1984; 289: 954-6.

2 Persson P-G, Ahlbom A, Hellers G. Inflammatory bowel disease and tobacco smoke - a case-control study. Gut 1990; 31: 1377-81.

3 Holdstock G, Savage D, Harman M, Wright R. Should patients with inflammatory bowel disease smoke? $B M \mathcal{F}$ 1984; 288: 362 .

4 Thornton JR, Emmett PM, Heaton KW. Smoking, sugar, and inflammatory bowel disease. $B M \mathcal{F} 1985 ; 290$ : 1786-7.

5 Vessey $M$, Jewell D, Smith A, Yeats D, McPherson K. Chronic inflammatory bowel disease, cigarette smoking and use of oral contraceptives: findings in a large cohort study of women of childbearing age. $B M \mathcal{Y} 1984 ; 288: 1307$

6 Franceschi S, Panza E, Vecchia C, Parazzini D, Decarli A, Bianchi Porro G. Nonspecific inflammatory bowel disease Bianchi Porro G. Nonspecific inflammatory bow

7 Tobin MV, Logan RFA, Langman MJS, McConell RB, Gilmore IT. Cigarette smoking and inflammatory bowel disease. Gastroenterology 1987; 93: 316-21

8 Benoni C, Nilsson $\AA$. Smoking habits in patients with inflammatory bowel disease. A case-control study. Scand $\mathcal{F}$ Gastroenterol 1987; 22: 1130-6.

9 Lindberg E, Tysk C, Andersson K, Järnerot G. Smoking and inflammatory bowel disease. A case control study. Gut 1988; 29: 352-7.

10 Silverstein MD, Lashner BA, Hanauer SB, et al. Cigarette smoking in Crohn's disease. Am $\mathcal{F}$ Gastroenterol 1989; 84: smoking $31-3$.

11 Lindberg E, Järnerot G. The incidence of Crohn's disease is not decreasing in Sweden. Scand $\mathcal{F}$ Gastroenterol 1991; 26: 495-500.

12 Boyko EJ, Perera DR, Koepsell TD, et al. Effects of cigarette smoking on the clinical course of ulcerative colitis. Scand f Gastroeneterol 1988; 23: 1147-52.

3 Dixon WJ. BMDP Statistical software manual. Berkeley, University of California Press, 1990

14 Samuelsson SM. Ulcerös kolit och proktit. Uppsala: University of Uppsala, 1976: 128. (Thesis.)

15 Harries AD, Baird A, Rhodes J. Non-smoking: a feature of ulcerative colitis. BMf 1982; 284: 706 .

16 Jick H, Walker AM. Cigarette smoking and ulcerative colitis. $N$ Engl F Med 1983; 308: 261-3.

17 Logan RFA, Edmond M, Sommerville KW, Langman MJS Smoking and ulcerative colitis. $B M \mathcal{F} 1984 ; 288$ : 751-3.

18 Wakefield AJ, Sawyerr AN, Dhillon AP, et al. Pathogenesis of Crohn's disease: Multifocal gastrointestinal infarction. Lancet 1989; ii: 1057-62.

19 Wakefield AJ, Sankey EA, Dhillon AP, et al. Granulomatous vasculitis in Crohn's disease. Gastroenterology 1991; 100: 1279-87.

20 Benoni C, Nilsson $\AA$, Nived O. Smoking and inflammatory bowel disease: Comparison with systemic lupus erythemabowel disease: Comparison with systemic lupus erythema-
tosus. A case-control study. Scand $\mathcal{F}$ Gastroenterol 1990; 25: tosus. A

21 Sutherland LR, Ramcharan S, Bryant H, Fick G. Effect of cigarette smoking on recurrence of Crohn's disease. Gastroenterology 1990; 98: 1123-8. 